\title{
CONHECER O ENTUSIASMO
}

Leonardo D'Avila de Oliveira Doutorando em Literatura - UFSC leonardo.davila.oliveira@gmail.com

Resumo: O entusiasmo é classicamente definido como aquilo que não é capaz de produzir conhecimento elaborado (epistéme). Entretanto, essa relação entre o pathos como inspiração e a filosofia, a lógica ou a ciência, geralmente foi evitada em detrimento de estudos que procuravam conceituar a inspiração artística em si. Nesse sentido, apesar do entusiasmo ter sido pensado de modos muito variados, e por vezes discordantes, como, na modernidade, em fanatismo para os classicistas ou dom universal para os românticos, todos mantêm-no como um antípoda do conhecimento científico. Entretanto, procura-se demonstrar algumas insurgências contra esse lugar comum a partir de textualidades da segunda metade do século XIX, mais especificamente em Flaubert, Walt Whitman e Henry James. Evidencia-se como em alguns escritos é possível notar gestos de pretensão gnoseológica em relação ao pathos, mesmo que para isso abandonem uma pretensão de verdade e reconheçam-se dotados de paixão.

Palavras-chave: entusiasmo; conhecimento; esteticismo.

Abstract: Enthusiasm classically has always been defined as that which is not capable of producing elevated knowledge (epistéme). However, this relationship between pathos as inspiration and philosophy, logic or science, has generally been supplanted by studies that sought to conceptualize artistic inspiration in itself. In this sense, despite enthusiasm was very different in many modes of thought, such as fanaticism among classicists or as universal gift by Romantics, all of them maintain it as an antipode of scientific knowledge. However, we try to demonstrate some insurgencies in textualities against this commonplace in the second half of the nineteenth century, specifically in Flaubert, Henry James and Walt Whitman. It is shown in some of those writings that there were gnoseological gestures that intended to deal with pathos, even if they have to abandon a claim to truth and recognize themselves endowed with passion.

Keywords: enthusiasm; knowledge; aestheticism.

1. A busca conceitual pelo entusiasmo historicamente o acatou enquanto fundamento da arte, princípio poético ou mesmo dom ao passo que, por outro lado, resta um problema correlato de motivo epistemológico que insistiu, por muito tempo, em permanecer irrespondido. Apesar da pergunta sobre a possibilidade do conhecimento do pathos enquanto inspiração poética ser fundamental, sendo inclusive o principal mote do célebre diálogo Íon de Platão, ela não suscitou tantas reflexões quanto a pergunta pelo que vem a ser a própria inspiração, a qual produziu um riquíssimo e vasto conjunto de concepções acerca do que é estar inspirado, tomado pelos deuses ou ainda de como pode algo estranho ser a causa dos versos ou do declamar poético.

$\mathrm{Na}$ modernidade, essa condição de negar a possibilidade de se conhecer o entusiasmo predominou. E, como era de se esperar, muito se escreveu sobre a inspiração em si e suas 
causas, virtudes ou perigos, como será visto nos próximos exemplos. Contudo, a noção foi alvo de opiniões e julgamentos dos mais discordantes e, por mais que, na maioria das vezes, as teorizações tenham se referido ao entusiasmo como uma noção positiva, em outras, no entanto, ele chegou a ser motivo de dúvida e reprovação. É comum, por exemplo, entre iluministas uma associação do entusiasmo à própria embriaguez, como ocorre na segunda edição do Dictionnaire Philosophique Portatif de Voltaire: “o entusiasmo é tal qual o vinho: pode excitar tanto tumulto nos vasos sanguíneos e tão violentas vibrações nos nervos, que a razão fica totalmente abolida". " Mesmo que Voltaire veja a possibilidade de um entusiasmo na poesia domado pela razão, sua posição chega a ser amena se comparada com a de John Locke, para quem o entusiasmo seria puro fanatismo, tendo em vista que aos que se dizem entusiasmados, seu estado mental apenas seria "um ignis fatuus que os encerra neste círculo: é uma revelação, porque eles firmemente acreditam nisso; e acreditam nisso porque é uma revelação". 2 Mas, por mais que esse tipo de conceituação negue a inspiração como fundamento universal das artes, também não desenvolve a relação entre entusiasmo e conhecimento, apesar de não se poder negar que foi elaborado com Locke, Hume ou Voltaire um certo pensamento sobre o assunto, ainda que de maneira velada, pois todos, em última instância, se negaram a uma tentativa de explicação racional sobre o entusiasmo.

As teorizações posteriores, por sua vez, não se diferenciam com relação à grande maioria das predecessoras quanto ao privilégio da discussão sobre o entusiasmo enquanto fundamento ou a causa da poesia em detrimento de uma reflexão que considere o lado epistemológico do assunto. Ainda que se verifique uma perda da carga pejorativa da inspiração no iluminismo, com os românticos o entusiasmo volta a ser utilizado para se referir à maestria artística ou à irrupção da beleza. Sendo assim, à época da disseminação da concepção romântica de arte, num dos embates literários mais célebres de todos os tempos, August Schlegel retoma o entusiasmo como fundamento a uma arte não alegórica e pouco apegada a formas clássicas, propondo, por sua vez, uma arte condizente com a força da espiritualidade, e já não mais oposta à razão. Para o autor, "a inspiração poética, encarada sob o ponto de vista mais inteligente, como a potência de conceber a ideia do belo e tornála sensível, é um dom disseminado pela humanidade toda". ${ }^{3}$ Essa concepção, ao menos na França, vale lembrar, teve sua propagação em grande parte em razão dos escritos Mme

\footnotetext{
${ }_{1}^{1}$ Voltaire. Dicionário filosófico, p. 164.

${ }^{2}$ Locke. Ensaio sobre o entendimento bumano, p. 973-974.

${ }^{3}$ Schlegel. "A crítica entre a história e a filosofia da arte", p. 512.
} 
Staël, para quem 'l'enthousiasme trouve dans la reverie du Coeur et dans l'étendue de la pensée ce que le fanatisme et la passion renferment dans une seule idée ou dans un seul objet". ${ }^{4}$ Ou seja, contrapõe-se ao sentido pejorativo que o entusiasmo havia recebido, uma virtude ampla e abstrata comum à emoção e ao pensamento, a qual perpassa o fanatismo pessoal ou a obstinação do escritor ou do mártir. Mas, por mais que se tenha explorado o ser do entusiasmo, não se tomou a sério o conhecer do entusiasmo. Ou seja, românticos e iluministas tinham em comum a negação da possibilidade de conhecer o entusiasmo.

Acerca dessa questão, até mesmo Julio Cortázar em Para una Poética, de 1954, problematiza a inspiração, mas para novamente afastá-la da epistéme dizendo que não é do interesse do poeta copiar o filósofo. "Más que El posible afán de conocer - que se da solo em poetas 'pervertidos' al modo alquimista - importa ló que clara u oscuramente es común a todo poeta: el afán de ser cada vez más". ${ }^{5}$ Cortázar coloca, portanto, o ser à frente do conhecer. No entanto, ao fazê-lo, tipifica a possibilidade do poeta pervertido, o qual teria em Rimbaud um grande exemplo. Mas o que vem a ser um poeta tarado por conhecimento? Que tipo de consequência traz essa atitude ou essa reação? Para demonstrar algumas tentativas de cartografia do entusiasmo no século XIX, e esquecendo-se um pouco Rimbaud, que certamente poderia ter sua teimosia incluída neste tema, serão investigados os casos de Gustave Flaubert e Walt Whitman, os quais, por mais que se distinguiam geográfica e formalmente, mantêm certo embate sobre o fundamento da poesia, apesar de já se poder perceber em ambos atitudes que visam conhecer de algum modo o próprio entusiasmo.

Sendo assim, em uma carta enviada a Louise Colet, datada de março de 1853, o autor de Madame Bovary sustenta um posicionamento que ainda guarda muito do ceticismo iluminista acerca da emoção na poesia, tendo em vista sua argumentação de que

também é o fanatismo da Arte que faz o sentimento artístico. A poesia não é senão um modo de perceber os objetos exteriores, um órgão especial que côa a matéria e que, sem mudá-la, a transfigura. Então, se se vê o mundo exclusivamente com essa luneta, o mundo será tingido por sua tinta, e as palavras para exprimir o sentimento se acharão pois numa relação fatal com os fatos que a terão causado. ${ }^{6}$

Essa modalidade de sentimento artístico, comum ao fanatismo, passa a entender novamente o entusiasmo como esforço do próprio artista, que compõe a poesia em conjunto com a realidade fatual. Se na concepção romântica a inspiração era considerada

\footnotetext{
${ }^{4}$ Madame de Staël. De l'Allemagne, p. 578-579.

${ }^{5}$ Cortázar. Obra crítica, p. 386.

${ }^{6}$ Flaubert. Carta a Louise Colet, p. 404.
} 
um dom subsistente a qualquer individualidade, Flaubert a toma como uma percepção e organização de objetos exteriores. Comparar o fundamento da poesia entre um autor romântico e outro posterior é sem dúvida uma tarefa difícil e certamente inconclusiva. No entanto, reformulando-se algumas perguntas, pode-se gerar novos pontos de fuga quando se passa a não mais apenas se questionar acerca do que vem a ser o entusiasmo, mas de como cada autor lida com a possibilidade ou impossibilidade de conhecê-lo. Sendo assim, antes de simplesmente considerar Flaubert como um anti-romântico, pode-se perceber que o autor dá uma ênfase nos elementos formais da arte. Isto indica que, por mais que considere o estilo em detrimento do dom, Flaubert desvia as atenções do sentimento artístico para dom pessoal e maestria formal, porém o sentimento em si a princípio permanece impensável, assim como era para os românticos. A crítica que Flaubert faz ao entusiasmo retoma o que há de espiritual na arte mais como ímpeto pessoal do que propriamente dom universal e reforça o apelo às formas em detrimento de uma manifestação sensível de uma beleza transcendente, mas ainda assim concorda com os românticos em deixar impensada a emoção. Sem dúvida não se pode deixar de notar nele uma atitude tipicamente latina que irá se reformular pouco tempo mais tarde quando em 1895 Paul Valéry declara que: "O entusiasmo não é um estado de alma do escritor", mas uma intenção maquinal, que deve ser prefixada pelo que escreve, havendo um espaço para a intelectualização da escrita em detrimento do fluxo de consciência ou da pura manifestação espiritual, pois é imperativo para autor "Escrever devendo ser, o mais solidamente e o mais exatamente possível, construir essa máquina de linguagem na qual o relaxamento do espírito excitado se consome em vencer resistências reais [...]". Novamente se nota uma atitude profundamente anti-romântica em relação ao passional da poesia; mas também romântica no que tange a se afastar da questão do conhecimento elaborado sobre o entusiasmo, propondo, antes de um abandono de si da parte do autor, uma resistência ao delírio puro.

Contudo, não se pode ocultar que Flaubert, no mesmo tempo em escreve suas opiniões adversas ao entusiasmo, ocupa-se de sua obra mais incompreendida, La Tentation de Saint Antoine, trabalho que perdura desde que viu o quadro de mesmo nome de Brueghel em Gênova em 1845 até sua publicação definitiva em 1874, na qual essa mesma recusa da inspiração ganha ares sonoros e coloridos em sua temática, mesmo que por um outro viés. Trata-se de uma narrativa fantástica escrita em linguagem que remonta ao apocalipse ou ao

\footnotetext{
${ }^{7}$ Valéry. Introdução ao método de Leonardo Da Vinci, p. 117.

8 Valéry. Introdução ao método de Leonardo Da Vinci, p. 119.
} 
rebuscamento de um Fausto de Goethe, na qual Santo Antão, asceta egípcio tido por fundador do monaquismo ocidental, refugiando-se no deserto para fugir das agruras da matéria, vê-se confrontado por forças demoníacas a todo instante. O deserto frio e opaco, vira delírio de paisagens e seres fantásticos, semelhantes aos que colorem quadros homônimos de Bosch ou Dalí. Sendo assim, o eremita é tentado por comida, por sedução luxuriosa, entre outras atrações carnais. A cada uma delas, mesmo à rainha de Sabá, Antão resiste abraçado à cruz. Porém o maior confronto se dá quando ocorrem confrontações de diversas concepções religiosas, já que Buda, Ísis, Manes, entre outros, vêm convencê-lo da verdade de suas doutrinas ante seu cristianismo ferrenho. O embate do fluxo de tentações se demonstra então um embate de verdades, que justamente vêm para acabar com a verdade única. Portanto, a recusa de Santo Antão, que perante cada tentação levanta a cruz, é tanto uma questão de recusa da alteridade, quanto de insistência em uma única verdade superior frente a todas aquelas verdades aparentes e errôneas derivadas do delírio. Isso se comprova porque, na trama, mesmo um acesso ao mundo inteligível, portanto superior ao sensível, é motivo de resistência, por exemplo quando se nota a aversão de Antão ao neopitagórico Apolônio de Tiana e seu discípulo Dâmis:

\footnotetext{
Apolônio: Deixa Dâmis! Ele crê, como um bronco, na realidade das coisas. O terror que lhe causam os deuses não permite que ele os compreenda. Só sabe descer ao nível de um rei presunçoso! Damis, meu filho, não me deixes!

- Recuando, Apolônio se aproxima da beira da escarpa, a ultrapassa e fica suspenso. -

Acima de todas as formas, para além da terra, para além dos céus, reside o mundo das ideias, pleno do Verbo! De um salto, transpomos o outro espaço e aprenderás na sua infinitude, o eterno, o absoluto, o ser! Vamos! Estende a tua mão! A caminho!

- Ambos, lado a lado, aos poucos, se erguem no ar.

Antão, abraçado à cruz, vê os dois subirem.

Desaparecem. ${ }^{?}$
}

Assim, o terror aos deuses dentro de si, de certa forma o terror ao entusiasmo, impede Santo Antão até mesmo de buscar as verdades inteligíveis pregadas pela tradição pitagórica de Apolônio ou mesmo Platão. Fiel à cruz, Antão resiste àquelas tentações e quimeras que lhe ultrapassam. Por outro lado, já existe uma certa gnoseologia do entusiasmo, ainda que na ascese, pois seu deparar-se contra todas as miragens e a sua obstinada resistência não deixa de ser também uma constatação, mesmo que completamente passional e, por isso mesmo, não científica. Ou seja, por mais que a tematização do entusiasmo não seja tratada epistemologicamente, há, pelo menos, uma preocupação gnoseológica.

\footnotetext{
${ }^{9}$ Flaubert. As tentações de Santo Antão, p. 104.
} 
O surgimento do problema gnoseológico, portanto da constituição de um conhecimento despreocupado com formalismos, em detrimento de um epistemológico, ou seja de conhecimento qualificado, como filosófico ou científico, também se faz presente do outro lado do Atlântico. Outro tipo de operação, que, ao mesmo tempo que nega o conhecimento do impessoal, reconhece-o de uma outra maneira mais passional é o de Walt Whitman na segunda metade do século XIX. Sendo assim, no final do último poema do conjunto intitulado Drum-Taps, publicado em 1865 em mais uma inserção no trabalho contínuo Leaves of Grass, Walt Whitman chama cantando pelo Mississipi, pelas pedras, pelas árvores e heróis que morreram na Guerra de Secessão norte-americana, quando obtém uma resposta. "And responding they answer all, (but not in words,) / The average earth, the witness of war and peace, acknowledges mutely". ${ }^{10}$

O testemunho da guerra, assim como a própria terra, portanto, respondem não por palavras, mas pelo silêncio ao canto do poeta, o qual, ao cantar, tangencia seu próprio substrato, contudo sem nunca reconhecê-lo propriamente, exceto por meras evidências. Eis que, além daquilo que o poeta pode falar, restaria o silencio que testemunha o impossível e a plenitude.

Contra essa atitude espirituosa, porém agnóstica de Whitman, Henry James prontamente publica uma nota avassaladora de Drum-Taps em Nation na edição de 16 de Novembro de 1865, na qual critica no autor a falta de bom gosto e excesso de lirismo, qualificando-o como um poeta menos importante. A maior crítica se dá sobre o próprio método através do qual Whitman faz poesia, de modo que James termina sua leitura com as seguintes palavras:

\begin{abstract}
Você deve esquecer a si mesmo em suas ideias. Suas qualidades pessoais - o vigor de seu temperamento, a grande independência de sua natureza, a ternura de seu coração - esses fatos são impertinentes. Você deve estar possuído, e deve se esforçar para possuir a sua possessão (possess your possession). Se em seu esforço você topar com a divina eloquência, és um poeta. Se a ideia que o possui é a ideia da grandeza da grandeza de seu país, então você é um poeta nacional, e não de outro modo". 11
\end{abstract}

Entusiasmo e silêncio não foram considerados como sinônimos de um princípio poético nesse contexto entre Whitman e James. Muito pelo contrário, Henry James afirma o entusiasmo, a divina eloquência, como antídoto para o lirismo. Sendo assim, para Whitman, além das suas descrições e das suas impressões individuais mediatizadas por palavras, haveria o silêncio; para Henry James, tratando do mesmo assunto, o verdadeiro

${ }^{10}$ Whitman. The Complete Poems, p. 350.

11 James. Literary Criticism, p. 634, tradução nossa. 
poeta é tomado pelo entusiasmo em um esforço "pessoal de despersonalização", que irá gerar palavras de eloquência divina. Ou seja, é possível afirmar que, enquanto Henry James vê o entusiasmo que gera a poesia na encarnação de uma forma, isto é, como performance, Whitman o toma como uma força maior que subjaz a escrita sem com ela nunca coincidir. Porém, mesmo que discordem sobre o que vem a ser o entusiasmo, há em ambos uma inegável preocupação gnoseológica. Essa disputa, no entanto, longe de ser um briga pessoal gerada no século XIX nos Estados Unidos, demonstra uma questão que sempre retorna. Não se trata apenas de ressaltar a mudez ou a possessão em si para justificar a poesia: mas se trata de demarcar justamente o re-conbecer da mudez (acknowledge mutely) em Whitman e o possuir a possessão (possess your possession) em James, tal como no terror aos deuses pagãos com Flaubert. Por mais que todas essas posições sejam notoriamente distintas, cada qual com sua própria individualidade, em ambas há em comum uma indagação ou ainda uma sutil cognição do entusiasmo, como um reflexo de paixão.

2. Essa indagação de entrever uma possibilidade gnoseológica ao entusiasmo, no entanto, não é de forma alguma novidade do século XIX ou de alguns autores específicos que tenham se deparado com o tema do entusiasmo. E tampouco é uma questão secundária. Aliás, pode ser afirmada como uma questão central da teoria da poesia, desde seus primórdios na antiguidade. Isso porque não é exatamente uma busca pelo fundamento do poético, mas principalmente a busca por um discurso que fundasse verdade o que motiva todo o diálogo platônico Íon. Apesar de nele se descrever a potência divina (theía dè dynamis) que acometeria os rapsodos, poetas e público, possibilitando então que se transmitisse a emoção proveniente das próprias musas, como se fosse por magnetismo, essa construção vem para dizer que Íon, sendo um rapsodo, confessa saber declamar Homero e apenas este. E, mesmo que fizesse os ouvintes chorar de cidade em cidade, Íon não poderia julgar se há verdade nos versos de Homero sobre cavalos melhor do que um cocheiro o faria, apenas por citar as empresas de Nestor, entre outros. Do mesmo modo, o rapsodo não poderia julgar versos em que se fala de poções de cura melhor do que um médico. Em outros termos, Íon, que se diz o melhor conhecedor de Homero, inclusive por ter ganhado competições de declamação, para o Sócrates platônico, não conheceria nada, pois apenas repete versos quando declama. Entre muitos outros exemplos no texto, destaca-se aquele que compara o comandante ao citarista, um que age por conhecimento e outro por arte. 
Sócrates: [...] Pois se você por acaso fosse ao mesmo tempo cavaleiro e citarista, você saberia que cavalos cavalgam bem e mal; mas se eu lhe perguntasse: "Por qual arte, Íon, você sabe que cavalos cavalgam bem - pela qual você é cavaleiro ou pela qual é citarista?", o que você me responderia?

Íon: Pela qual sou cavaleiro, eu responderia. ${ }^{12}$

Portanto, o proceder rapsódico acometido pelo entusiasmo não fundaria nenhuma forma de conhecimento (epistéme) sobre sua atividade mimética. A partir disso, a discussão passa a ser a de que se poderia trabalhar com as palavras, e até mesmo com o verso, de uma forma não artística, de forma a abandonar a techne, para dar lugar à dialética (dialégesthai), e assim entrever o lógos. Em outras palavras, Platão diz que um cowboy pode conhecer e explicar melhor do que qualquer poeta as passagens da Ilíada que tratam de cavalos. E assim se daria com outros ofícios, como médicos, citaristas, etc. Dito de outra maneira, o saber qualificado, epistêmico e digno da lógica é afirmado como antípoda da atividade poética, já que os poetas e rapsodos falam por delírio e não por conhecerem o sentido do que falam.

Uma segunda consequência desse posicionamento é a de que Íon marca muito bem os primórdios do cânone maior do esteticismo: aquele de que a arte é algo divino e de impossível compreensão em seus fundamentos, mas, por outro lado, - e principalmente que a arte não funda nenhum saber dotado de verdade. À exceção de um saber sobre a própria versificação, o que inclusive Sócrates aceita em Íon, o rapsodo, quando tomado pelo pathos, não é capaz de discernir nenhuma verdade e, portanto, não conhece com autoridade aquilo que declama. Vale aqui lembrar que em seu tratado sobre o Sublime, Longino já aventava de certo modo um contraponto à posição platônica quando punha a própria lida artística como disciplinadora do emocional, na medida em que, para ele, "sem os preceitos técnicos, sem apoio nem lastro, abandonados apenas a seus ímpetos e arrojo deseducado, os gênios correm perigo maior, pois, se muitas vezes precisam de espora, muitas outras, de freio". ${ }^{13}$

No entanto, é surpreendente que a pergunta sobre o conhecimento do entusiasmo permaneça aberta tanto na antiguidade quanto no iluminismo, ainda que haja respostas completamente contrárias. Isso porque na filosofia de Platão referente ao entusiasmo, aquele que foi tocado pela afeição (pathos) é conduzido por uma comunicação divina e exterior a si não podendo, portanto, fundar uma verdade ou um saber (epistème) porque não fala por si. E por outro lado é paradoxal que, de um modo absolutamente contrario a essa

12 Platão. Íon: sobre a inspiração poética, p. 49.

${ }^{13}$ Longino. Do Sublime, p. 72. 
concepção clássica, na modernidade o afeto passe a ser considerado impensável por ser justamente uma impressão meramente subjetiva, portanto, restrita a si, não podendo, assim, fundar qualquer saber, a exemplo das teorizações estéticas de Locke, Hume ou Kant, pois para este último, "um juízo estético não é nenhum juízo objetivo e de conhecimento". ${ }^{14}$ Em outras palavras: Platão diz que o entusiasmo não gera conhecimento porque não é algo condizente com aquele que fala, isto é, porque lhe falta subjetividade. Os modernos dizem que o entusiasmo não gera conhecimento porque é uma noção subjetiva. Desse modo, não parece viável entender que a explicação sobre a impossibilidade do pathos gerar saber se dê em função de alguma concepção de sujeito ou mesmo de sua falta ou de sua aniquilação, pois independentemente da época, o que permanece incólume é a inescrutabilidade das emoções, o que leva Ramón Xirau a alertar sobre o abismo que se construiu acerca do dogma da inspiração enquanto delírio inefável e da ciência enquanto conhecer sem emoção: "dirigida ao conhecimento, a inteligência; dirigida ao erro e à falsidade, a emoção. Essa cisão é frequente; essa cisão é também falaciosa. E o é porque tanto a emoção como a inteligência são parte da razão". ${ }^{15}$

Retomando-se, portanto, a ocultação da pergunta epistêmica pelo entusiasmo na modernidade, observa-se a permanência da dicotomia entre aquilo que é lógico, verdadeiro, científico e aquilo que é divino, sensível, emocional tanto em românticos quanto em iluministas e seus respectivos sucessores. Ou seja, a única definição segura a ser dada sobre o entusiasmo é a de que, tal como a doxa, que não cria epistéme. Portanto, a discussão aventada no século XIX sobre o entusiasmo ser a incorporação de formas clássicas ou então a uma irrupção sensível do belo, em ambos os casos, reforça a ênfase sobre a inescrutabilidade do entusiasmo, havendo um predomínio da fundamentação do desconhecido em vez de um conhecimento do fundamento na poesia. Todas essas teorizações velam o dogma de que a emoção não gera conhecimento, ou por ser transcendente ou por ser um esforço meramente subjetivo.

Entretanto, a situação muda completamente quando se trata a querela entre o reconhecer a mudez de Walt Whitman e o possuir a possessão de Henry James, pois surge uma nova questão: o que é possuir ou re-conhecer? O que também significa apavorar-se com os deuses dentro de si? Certamente essas atitudes não são conhecimentos rumo a uma verdade superior e objetiva ou à ciência, mas são ainda assim modalidades precárias de cognição. O possuir a possessão e o reconhecer a mudez esclarecem que a inspiração e

${ }^{14}$ Kant. Crítica da Faculdade de Juíro, p. 82.

15 Xirau. Ensaios críticos e filosóficos, p. 198-199. 
conhecimento são dois temas que caminham paralelamente e de modo independente do que se possa entender por inspiração ao passo que a pergunta pelo conhecer o entusiasmo, por mais que seja cientificamente ou filosoficamente irrespondida, não deixa de estar implicitamente presente.

3. O irmão de Henry James, o filósofo William James, por sua vez, foi bastante explícito ao trabalhar com as emoções relacionado-as com essa questão epistemológica que se pretende evidenciar. É possível dizê-lo porque em Principles of Psychology, publicado em 1890, William James expõe um capítulo consagrado às emoções, no qual apresenta uma interessante teoria que leva em consideração a percepção, as alterações corporais e as emoções em sentido estrito. Para o autor, que já tinha conhecimento dos trabalhos do médico dinamarquês Carl Lange, as emoções não seriam estados gerados após alguma percepção sensorial e que, sucessivamente, seriam capazes de promover alterações corporais, como arrepios, choro, rubor, fuga, entre outros. A teoria de James considera que, após a percepção sensorial, há instantaneamente uma alteração corporal para só então haver uma resposta emocional.

\begin{abstract}
Nossa maneira natural de pensar sobre essas emoções primárias é que a percepção mental de algum fato estimula a afecção mental chamada emoção, e que este último estado mental impulsiona a expressão corporal. Minha teoria, ao contrário, é a de que as mudanças corporais seguem diretamente a percepção do fato estimulante, e que nossa sensação dessas mesmas mudanças como elas ocorrem É a emoção. [...] No caso dos estados corporais não seguirem a percepção, a última seria apenas cognitiva na forma, portanto sem cores, destituída de calor emocional. Nós deveríamos, se assim fosse, ver um urso e julgar se é melhor correr, receber um insulto e pensar em revidar, mas não nos sentir com medo ou bravos. ${ }^{16}$
\end{abstract}

Sendo assim, não se chora porque se está triste, por exemplo após o conhecimento de se haver perdido uma grande fortuna; mas ao contrário. Para William James, após a percepção de algo chocante, primeiro haveria a resposta corporal, como o choro, para só então haver a tristeza, de modo que as emoções não se separam e não podem ser pensadas separadas de respostas corporais e, além disso, a emoção não seria um estado abstrato e universal guardado em algum lugar desconhecido que subsiste fora do corpo e fora do indivíduo. Por isso, explica James, as pessoas reagem com emoções diferentes a estímulos sensoriais idênticos, sendo então impossível isolar as emoções das histórias pessoais e da resposta impulsiva do corpo. Isso explicaria porque duas pessoas podem reagir diferentemente à mesma música, por exemplo. Tanto por lhe agradar ou agredir a audição, quanto por remeter a uma história pessoal agradável ou terrível, as respostas corporais

16 James. The Principles of Psychology, p. 450, tradução nossa. 
serão diferentes e, por isso, para se conhecer qual tipo de emoção acomete determinado sujeito não se pode buscar no próprio objeto sensível a resposta, mas nas próprias alterações corpóreas.

No entanto, por mais que essa fosse a ordem padrão recepção e propagação da emoção, para James, a existência de emoções ascéticas não fica descartada, principalmente quando se trata de percepções calcadas de fortes hábitos de intelectualismo ou axiologia, sendo o caso das emoções agenciadas por um controle de percepção. Portanto, ao tratar diretamente das emoções com relação à arte, William James faz uma dura crítica ao que teria se tornado a percepção de objetos estéticos, supostamente causadores de emoções mais refinadas do que puramente sensoriais. Ao passo que o gosto clássico seria mais preso à forma e à percepção direta, o gosto romântico apelaria a essas emoções secundárias, no entanto, recaindo inevitavelmente em uma série de julgamentos morais que nada mais seriam do que atos cognitivos e sem emoção verdadeira.

\begin{abstract}
Ainda, quando uma longa familiaridade com certo tipo de efeitos, mesmo estéticos, cegou meras estimulações emocionais como tendo afiado o gosto e as opiniões, nós recebemos, sim, emoção intelectual, se for possível dizê-lo, pura e imaculada. E a sua secura, sua palidez, a ausência de qualquer brilho, como deve se dar na mente completamente expert do crítico, não apenas mostra como é totalmente diferente das emoções mais primárias que consideramos antes, mas nos faz suspeitar que quase toda diferença jaz no fato de que a caixa de ressonância corporal, vibrando em um caso, é, no outro, muda. ${ }^{17}$
\end{abstract}

Os diagnósticos de William James em seu contexto chamam muito a atenção porque a emoção passa a não mais ser pensada fora do corpo, e, se há algum afastamento entre essas duas noções, isso não se dá de forma automática, mas mediante hábito e doutrinamento. Portanto, a retirada das emoções de um plano superior para ser colocada como questão corporal pode explicar porque há divergência de gosto e, mais ainda, porque a maioria das pessoas simplesmente não gosta de poesia ou música erudita.

Obviamente não se pode deixar de notar em William James seu forte utilitarismo, o qual quer achar as causas das emoções diretamente nas consequências corporais. Entretanto, ainda assim, o autor faz uma severa crítica ao esteticismo, ainda no século XIX, ao tentar conhecer de alguma maneira o entusiasmo, um pouco depois do trabalho de Nietzsche no mesmo sentido do outro lado do Atlântico. E, se o autor fez uma crítica contemporânea, porque estava à frente de seu tempo, ele o fez inteiramente por recolocar a questão epistemológica sobre a emoção. Nesse sentido, William James a todo tempo opõe emoção com cognição para dizer que ambas as noções não podem ser separadas e não

\footnotetext{
17 James. The Principles of Psychology, p. 471, tradução nossa.
} 
necessariamente devem permanecer impensadas por algum obstáculo ontológico, mesmo que para isso tenha de se desistir de tentar achar no entusiasmo algum fundamento ou verdade.

Friedrich Nietzsche, alguns anos antes, combatera essa mesma característica de obstinação pela necessidade que era nutrida por muitos utilitaristas até mesmo em pensamentos sobre a arte, ocasionando um paralelo problemático entre verdade e vida. Nietzsche, ao tratar de verdade e arte, mesmo sendo contrário à causalidade utilitarista, condena a tradição socrática de busca pelo conhecimento verdadeiro e, a princípio, a própria indistinção entre saber e sentimento. Para o filólogo alemão, essa verdade, esse conhecimento refinado, tornou-se uma máquina capaz de aliciar junto a si outras no propósito maior da especulação que visa o bom, o belo, entre outros fins. Portanto, em crítica tanto ao utilitarismo quanto ao esteticismo, afirma:

\begin{abstract}
Não somente utilidade e prazer, mas todo gênero de impulsos tomou partido na luta pelas "verdades"; a luta intelectual tornou-se ocupação, atrativo, dever, profissão, dignidade -; o conhecimento e a busca do verdadeiro finalmente se incluíram, como necessidade, entre as necessidades. A partir daí, não apenas a fé e a convicção, mas também o escrutínio, a negação, a desconfiança, a contradição tornaram-se um poder, todos os instintos 'maus' forma subordinados ao conhecimento e postos ao seu serviço, e ganharam o brilho do que é permitido, útil, honrado e, enfim, o olhar e a inocência do que é bom. O conhecimento tornou-se então parte da vida mesma e, enquanto vida, um poder em contínuo crescimento. ${ }^{18}$
\end{abstract}

Eis que, todos os sentimentos contrários a uma hierarquização teleológica, acabaram por ser agenciados em função de um saber científico que prima pela invenção de uma verdade. No entanto, as reflexões de Nietzsche ressaltam que o próprio conhecimento científico, bem como o próprio empenho rumo à verdade não deixa de ser também de possuir uma forma de pathos.

Seriedade com a verdade! Que diferentes coisas entendem as pessoas por essas palavras! As mesmas opiniões e tipos de prova e demonstração que um pensador acha uma leviandade à qual, para sua vergonha, ele sucumbiu nesse ou naquele instante - precisamente essas opiniões podem dar, a um artista que com elas depara e vive algum tempo, a consciência de que se tornou profundamente sério com a verdade e de como é admirável que, embora artista, ele mostre também o mais sério desejo do contrário da aparência. Então é possível que, justamente com o pathos de sua seriedade, ele traia o modo superficial e limitado com que até agora o seu espírito se moveu no campo do conhecimento. ${ }^{19}$

18 Nietzsche. A Gaia Ciência, p. 129.

${ }^{19}$ Nietzsche. A Gaia Ciência, p. 109. 
Do mesmo modo que um cientista obstinado pela busca por uma verdade por trás das aparências ou na seriedade de uma avaliação lógica sobre verdade ou inverdade de proposições não está isento de uma forma disfarçada de paixão, o artista também não é puramente passional na medida em que se deixou absorver pelo preconceito empírico ou a busca pela seriedade conceitual. O que mais vale dessa análise de Nietzsche certamente não se trata do julgamento que o autor faz sobre seu tempo ou mesmo sobre um modelo de cultura, mas tem seu aspecto mais curioso e peculiar na maneira em que coloca ciência e a arte interpenetráveis e, sendo assim, expõe que a verdade não pode nunca ser uma verdade ideal, pois, ela também é fruto das paixões e com elas lida a todo instante. Eis que, no lugar de uma verdade como revelação da ideia ou decorrência de algum conteúdo lógico, Nietzsche entende-a com suas precariedades, percalços e reviravoltas, já que são mais do que formas, construções resultantes de forças.

Nietzsche, portanto, não exatamente recoloca a questão epistemológica para pensar a emoção sem fazer disso outra teoria estética, mas o autor relativiza a própria noção de conhecimento científico, destacando que as verdades mais lógicas não são nada além de aparências fiéis em repetir aquilo que já é usual, mas ainda assim aparência; nisto, é a própria noção epistemológica que vem a fraquejar. Já não há sentidos seguros ou "a verdade" por trás de versos. Ainda assim, vale ressaltar que Nietzsche e W. James, por mais que não estejam de acordo com relação ao que seja o entusiasmo, concordam em explorar a distensão existente entre episteme e pathos para, ao final, e de modos distintos, exporem que a emoção e sua relação com a cognição não devem permanecer impensadas. Importa salientar que, conforme Nietzsche, existem outras formas de regimes de sentido que não são conhecimento qualificado, como o filosófico ou o científico, episteme. Esse tipo de conhecimento que não dispensa o passional e que goza em não advir mais do que mero saber é da ordem da gnose. Pode-se assim melhor esclarecer as palavras de Ramón Xirau quando afirma que "conhecer não é apenas analisar (palavras, conceitos, ideias). Conhecer é, conjuntamente, perceber, sentir, nascer com o mundo, com os outros, com o Outro. Não dizia Claudel que o conhecimento é co-naissance?”. ${ }^{20}$

Nesse sentido, tanto o reconhecimento de Whitman, quanto a possessão de James podem vir a ser enquadrados como duas maneiras bastante individualizadas de se lidar com o entusiasmo, certamente mais gnósticas do que epistêmicas, mas nem por isso deixam de ser maneiras próprias de conhecer. Rumo a uma tentativa de conclusão, vale repetir que,

\footnotetext{
20 Xirau. Ensaios críticos e filosóficos, p. 199.
} 
enquanto o gosto clássico nega simplesmente possibilidade de se conhecer o entusiasmo, ou porque simplesmente é uma abstração vazia ou, quando muito, um fanatismo pessoal, o gosto romântico, por mais que reconheça o entusiasmo como dom do espírito, não coloca nenhuma possibilidade de conhecê-lo simplesmente porque se trata de algo que transcende a compreensão ou a representação. Ora, há de se convir que a distinção entre o clássico e o romântico em nada ajuda para a principal questão que se pode fazer sobre o entusiasmo, justamente sobre a impossibilidade ou não deste formar conhecimento elevado. Enfim, o entusiasmo possui vários conceitos, mas nenhum deles é conclusivo, o que seria resumido por Benedetto Croce em: "o sentimento ou o estado de alma não é um conteúdo específico, mas é o universo todo, olhado sub specie intuitionis". 21 Portanto, muito mais importante do que se decidir por considerar o sentimento como fundo da poesia ou uma alegoria de sua formação, importa entrever, em suas próprias individuações contrapostas a um conceito universal e vazio, os modos pelos quais se deu a lida com o entusiasmo, considerando-se ele da maneira que for. Examinar em cada caso uma lida descomprometida com a verdade ou inverdade de um fundamento da poesia, seja na ojeriza, na encarnação ou na teimosia consiste em ler os infinitos empenhos de cognição emocionalmente parciais sobre o poema, isto é, reflexos de paixão. Ao se ressaltar os enfrentamentos ao dogma de que não se pode reconhecer o pathos, ou seja, na evidenciação da própria separação entre epistéme e entusiasmo, gestos perversos ou alquímicos de terror aos deuses em Flaubert, possuir a possessão em Henry James ou re-conhecer a mudez em Whitman podem ser lidos como tentativas trágicas de deslocar a própria poesia de seu lugar ou não-lugar privilegiado, perfazendo um movimento que vinha sendo realizado também no campo filosófico por autores tão díspares quanto William James ou Nietzsche, isto sem se considerar aquele que mais evidenciou a problemática, Henri Bergson. Eis que os gestos de escritores em seus reflexos de paixão tiveram uma atitude gnoseológica e podem ensinar que, para além de um conhecimento sobre o fundamento ou de uma fundamentação do desconhecido, também é possível Re-conhecer, a cada vez, o desconhecido.

\section{REFERÊNCIAS}

Aristóteles; Horácio; Longino. A Poética Clássica. Tradução de Jaime Bruna. São Paulo: Cultrix, 2005.

Cortázar, Julio. Obra Crítica. Vol. 2. Buenos Aires: Suma de Letras Argentinas, 2004.

${ }^{21}$ Croce. Breviário de Estética/ Aesthetica in nuce, p. 56-57. 
Croce, Benedetto. Breviário de Estética/Aesthetica in nuce. Tradução de Rodolfo Ilari Jr. São Paulo: Ática, 2001.

Flaubert, Gustave. "Carta a Louise Colet", em: Acízelo, Roberto (Org.). Uma ideia moderna de literatura. Chapecó: Argos, 2011, p. 404-405.

James, Henry. Literary Criticism. Nova Iorque: The Library of America, 1984.

James, William. The Principles of Psychology. Vol. 2. Londres: Macmillan, 1890.

Kant, Immanuel. Crítica da Faculdade de Juíro. Tradução de Valério Rohden e António Marques. Rio de janeiro: Forense Universitária, 2010.

Locke, John. Ensaio sobre o entendimento bumano. Vol. 2. Tradução de Eduardo Abranches de Soveral. Lisboa: Caloustre Gulbenkian, 1999.

Nietzsche, Friedrich. A Gaia Ciência. Tradução de Paulo César de Souza. São Paulo: Companhia das Letras, 2012.

Platão. Íon: Sobre a inspiração poética. Tradução de André Malta. Porto Alegre: L\&PM, 2011.

Staël, Madame de. De l'Allemagne. Paris: Librairie de Firmin Didot Frères, 1865, p. 578-579.

Schlegel, August. "A crítica entre a história e a filosofia da arte", em: Acízelo, Roberto (Org.). Uma ideia moderna de literatura. Chapecó: Argos, 2011, p. 511-513.

Valéry, Paul. Introdução ao método de Leonardo Da Vinci. Tradução de Geraldo Gérson de Souza. São Paulo: Editora 34, 1998.

Voltaire. Dicionário fillosófico. Tradução de Bruno da Ponte e João Lopes Alves. São Paulo: Abril Cultural, 1978.

Whitman, Walt. The Complete Poems. Londres: Penguin Books, 2004. [Folhas de Relva. Tradução de Rodrigo Garcia Lopes. São Paulo: Iluminuras, 2005]

Xirau, Ramón. Ensaios críticos e filosóficos. Tradução de José Rubens Siqueira de Madureira. São Paulo: Perspectiva; Edusp, 1975. 